\title{
Revising a Civil and Environmental Engineering Capstone Design Course
}

\author{
Douglas B. Cleary, Kauser Jahan \\ Rowan University
}

\begin{abstract}
The current paper describes the development and subsequent revision of the capstone design course for civil and environmental engineering students at Rowan University. Students take the course in both the fall and spring terms of their senior year. The course challenges and allows the students to demonstrate the engineering skills they have acquired through the undergraduate curriculum. The course was developed following a review of other capstone courses described in literature. Open-ended design projects are developed with assistance from industry advisors and presented to the students at the start of the course. The students then spend two semesters preparing solutions to the problems. The first year the course was offered went much as expected based on the instructors' previous experiences. Students complained of vague instructions, too much work, and lack of experience. However, additional student concerns with fairness and inequitable workloads were expressed. Refinements to the project selection process and course administration were made to address these concerns.
\end{abstract}

\section{Introduction}

The relative newness of the Civil and Environmental Engineering program at Rowan University offers many opportunities to study how other programs prepare engineering students and to revise and adopt the best practices of these programs. Two faculty members developed the capstone design course following a review of capstone courses offered by other programs. They also drew on their own previous experiences with similar courses and their experiences in industry. The Civil Engineering Design Project is the culminating design experience for the graduating seniors. The Design Project is a sequence of two 2-credit hour courses during the senior year. The senior civil and environmental engineering students work in teams of 4 or 5 students to solve an open-ended design project. Local engineering firms provide the projects and representatives from these firms participate in the evaluation process. The projects are either current projects the firms are working on simultaneously or are projects the firms have already completed. Students must prepare engineering plans, specifications, cost estimates, and written and oral project reports. Because the course extends over two semesters, an attempt is made place issues such information collection, planning and preliminary or concept design during the first semester with more detailed design during the second term.

The Design Project course was designed with the ABET 2000 criteria (ABET, 1999) and the concerns of industry in mind. Some of these concerns include lack of team skills, poor written and oral communication, lack of ability to consider alternatives, inability to synthesize components into a system, and weakness in economic analysis ${ }^{1-7}$. 
The first year the course was offered went much as expected based on the instructors' previous experiences. Students complained of vague instructions, too much work, and lack of experience related to specific project tasks. However, additional student concerns with fairness and inequitable workloads were expressed. This paper contains details of how the capstone design course was established and subsequently modified to address the lessons learned the first year.

\section{Review of Other Capstone Courses}

The first step in the development of the capstone course in civil and environmental engineering at Rowan University was a review of other capstone courses. The starting point for this was the survey of North American capstone courses conducted by Todd, et. al. ${ }^{8}$ and a later follow-up paper ${ }^{9}$. Among the findings are:

- Most civil engineering capstone projects are simulations of real-world problems.

- Approximately half of the courses are 1 quarter or semester and half extend over two or more quarters or semesters.

- Most capstone courses include only limited instruction time with only 7\% providing more than 3 hours per week. The majority of the time is allocated for students to work on the project.

Other findings were that most programs involve teams of less than six students with one team assigned to each project. Faculty roles vary from models in which a faculty member is responsible for a student or team, models with one or two professors responsible for administering the entire program, and models in which faculty consult and evaluate projects but are not directly responsible for any specific student or team. Many projects are now sponsored by industry.

The formats of capstone projects are becoming more structured with many programs going to an imaginary engineering company format ${ }^{9}$. Various forms of this model seem to be common in civil engineering programs. Knox ${ }^{4,10}$ describes a civil engineering capstone course which consisted of a one-semester project. Student teams of 4 to 5 civil or environmental engineering students each developed a technical solution to the same problem. The course instructor serves as a project facilitator and the rest of the faculty members have a limited role as consultants. Each student team has a leader. An industry representative provides the project, serves as the client and is involved in the evaluation of student work. Frequently one semester's project builds on the previous.

Morris ${ }^{11}$ describes a model in which a single semester-long project is assigned with an attempt to encompass environmental, geotechnical, water resources, transportation, and structural engineering. Two course coordinators serve the role of principles of the firm and the rest of the faculty serves in an advisory role. Based on the nature of the project, the students are divided into discipline specific design teams. Each team selects a team coordinator who serves the role of discipline lead. The students also select a project coordinator who serves the role of project manager. The discipline teams and individual team members have specific tasks that must be completed. The work of the teams must also be coordinated so the project as a whole comes together. This model is very close to the structure of many engineering firms. 
Both of the models described lack one important feature of a real industrial setting. The engineering staff is composed entirely of entry-level engineers. Course coordinators, faculty consultants, industry liaisons, and information sessions can be used to help bridge this experience gap.

Project deliverables most commonly include written and oral design reports, design drawings, specifications and cost estimates. Grades may be assigned based only on the group results or through a combination of team and individual grades ${ }^{9,10}$. A peer evaluation component may be incorporated into the grade. Sometimes industrial sponsors are included in the assessment of the student projects ${ }^{9,12}$. It is often acknowledged that evaluation of the student work in capstone projects is difficult ${ }^{9,11}$.

\section{Overview of the Civil Engineering Capstone Project at Rowan}

The Civil and Environmental Engineering program at Rowan University uses a two-semester format for the capstone course. The course is 2-credit hours each term. The two-semester structure allows the students to focus on planning issues and alternative evaluation during the first term with more focus on design activities during the second. It also provides an opportunity for the students to go through a revision cycle with their design work.

The CEE curriculum allows students to pursue one of two emphasis tracks, infrastructure or environmental engineering. Students in either track take a minimum of two courses each in the water resources, structures, and geotechnical areas as well as Surveying, Introduction to Environmental Engineering and common courses in statics, mechanics, materials science, and professional practice. There is also an eight-semester sequence of engineering clinics. The environmental track also includes four additional courses in environmental engineering while the infrastructure track has two additional structural engineering and two transportation engineering courses. The curriculum results in students with a broad view of civil engineering. The department considered using separate capstone projects for each of the tracks but quickly rejected this in favor of a common project for all of the students. The justification for this was giving students in each track more exposure to the other. It was also clear that the vast majority of the curriculum was common between the two tracks.

Industry sponsorship of projects is sought. In general CEE tries to select a project that encompasses at least several of the sub-disciplines offered in the curriculum. Even relatively simple engineering projects will offer many opportunities for and require the students to research methodologies they may not have seen in the classroom. Industrial sponsors may have already completed the projects themselves or they may be addressing them simultaneously with the students. Rowan CEE does not currently use projects for the capstone that the students would be the only ones investigating, although those types of projects will often appear in the clinics.

The typical graduating class in CEE at Rowan will have between 10 and 20 students. The students work in faculty-selected teams of 4 or 5 students. Each team works toward an independent solution to the same problem. One or two faculty members coordinate the course. The coordinator(s) are responsible for selecting the project and administering the course 
including the bulk of the evaluation effort. The remaining faculty serves as consultants to the students and coordinator. The student teams function as independent consulting firms with one student serving as the team leader. It is anticipated that within a team, individuals will split the work along discipline specific lines. However, students are expected to be familiar with all aspects of the work and will likely have to carry part of the load in more than one sub-discipline. The industry sponsors initially present the project to the student teams and attend and assist in evaluating mid and end-of-semester oral presentations. The industry sponsors also provide pertinent site data and help the coordinators scale the project to a level that can be managed by senior engineering students.

Deliverables will vary from project to project and term to term but will generally consist of written and oral midterm project reports, final written oral design reports, design drawings, specifications and cost estimates. The teams prepare an estimate of their engineering fees at the start of the project and are required to track their design costs throughout. Each team must also keep a project notebook which contains phone memorandum, meeting minutes, design calculations, and similar items.

The course has very little lecture component. Topics such as professional licensing, project finance, ethics, law, marketing, specifications, and cost estimates are addressed in a separate course ${ }^{14}$. The bulk of the time was set aside for the students to work with some time used for progress meetings, limited instruction, and presentations.

\section{The First Rowan CEE Capstone Project and Results}

The first capstone project was sponsored by an affiliate of a local water utility. Because the utility had limited well capacity, it relied on purchased potable water from an adjoining utility to supply its storage reservoirs and distribution network. The utility's storage and distribution system included three reservoirs, one ground level tank, and one elevated tank. The storage facilities were located at four locations within the water utility's boundaries. Two of the reservoirs were located on one site and were originally constructed in the mid-1800's. The liners and covers of these two reservoirs had once again reached the end of their design life and were requiring frequent repair. In addition, the utility believed it had excess storage capacity at this facility which resulted in slow water turnover and potential water quality concerns. The problem posed to the student teams was to evaluate the storage capacity of the entire system and make recommendations regarding the future of the two storage reservoirs of concern. First semester planning and design considerations included:

- the analysis of system storage requirements and the best way to provide these requirements including retirement of facilities, expansion of facilities and replacement of facilities,

- replacement of the cover/liner system at specific reservoirs including material selection and evaluation of a rigid cover system,

- embankment stability concerns,

- modifications to existing reservoirs to address water quality concerns,

- consideration of costs in all alternatives. 
For the second semester, the teams were presented with a scenario in which two design alternatives were carried forward into a design phase, (1) the removal of one reservoir and a new cover/liner system for the other and (2) the replacement of both reservoirs with a cast-in-place concrete reservoir. The second alternative was presented as potentially having a long-term maintenance advantage that could possibly justify the initial cost. It was also presented to introduce structural design into the problem. While the first semester primarily focused on planning issues with only enough design to provide cost data, the second semester required more detailed design work. Students were required to submit a drawing set that included a cover and index page, topographic and boundary sheets, a demolition plan, site plan, utility plan, grading and storm drainage plan, detail sheets for the liner system, and structural sheets for the concrete reservoir.

In some ways the results were better than expected and in others the CEE faculty was surprised. The students did a good job of evaluating the alternatives and their recommendations paralleled the water utility's own evaluation surprisingly well. Students were able to prepare all of the required deliverables with varying degrees of quality. The coordinators' and other CEE faculty members' evaluation of course found some problems including student procrastination and a poor job of economic analysis of alternatives. While students seemed to appreciate the industry link and felt the project was a "real-world" experience (with the exception of the efforts to introduce a structural component) they were frustrated by what they considered an excessive workload and vague guidelines. The students also were frustrated by the open-ended nature of the work and the fact that nothing looked like what they had done in any of their previous homework. As the project progressed, the coordinators also realized the work was not quite within their own realm of specialization or experience. All of these findings were similar to those reported by others ${ }^{4,11}$. However, one additional student concern caused some consternation among the faculty. Many students felt their teams had individuals who did not carry their burden of the load and that the "slackers" would receive an equal reward for lesser work. These comments occurred even though peer evaluations were conducted throughout the semester and the course criteria noted that the peer evaluations were used in part to determine the final grade. In fact, one peer evaluation form was received with a long letter asking what the point of a peer evaluation was when it was a team project and team grade.

\section{Revisions to the Capstone Course}

The end-of-course evaluation by students and faculty indicated that some revisions would benefit the capstone design course. The revisions were addressed during planning for the next year and focused on four general areas. These areas were (1) project selection, (2) student skills and training, (3) student procrastination, and (4) "fairness" and "slacker" issues.

The fairness issue was tackled first. Clearly there was a flaw in administering the course. Reflection identified two revisions that may address the problem. The grading system presented to the students indicated that peer evaluations accounted for $10 \%$ of the grade. The only other individual component to the grade was $10 \%$ related to the final oral presentations. Eighty percent of the course grade would be based on team products. Assuming that everyone would get at least some credit in each of the individual categories then it was likely that the individual components would not move someone more than a letter grade. Students probably correctly 
surmised that a slacker is not overly concerned with that lower grade and therefore has little motivation to contribute more than the bare minimum. The real injustice as far as the other students are concerned is that they then must increase their own efforts to overcome the weak link on the team and achieve the grade they deserve. This extra effort however also undeservedly rewards the slacker.

The peer evaluation form itself also probably caused some of the problems with slackers. The form used was very simple. It simply asked each student to write their impressions of their teammates and their contribution to the project. No guidelines were given to help students categorize the evaluation (e.g. no rating scale was provided) and it was not clear if they were to rate technical ability or contributions and commitment to the team effort. Also, students did not receive enough feedback following the submission of the forms. Some of the student who were not performing to teammates' expectations were probably not aware there was a problem.

For the following year a new peer evaluation form and process based on the work of Felder was adopted ${ }^{13}$. This form clearly indicated that the students were to reflect on their teammates' efforts and contribution to the team, not technical abilities. The form also provided a qualitative scale using terms such as excellent, ordinary, or deficient. Brief definitions of each of these rating levels were also provided. This form helped clarify that this was a team effort. Weaker students also did not need to be concerned if they had lesser technical abilities as long as they made good faith efforts to contribute. The peer evaluations were not identified as a fixed percentage of the grade. It was only indicated that they would be used to adjust the team results. Feedback would be given immediately following submission of the forms.

The coordinators did not elect to add additional individual line items to the grading system. Individual written assignments related to specific tasks or brief quizzes related to the project were considered. However, the coordinators decided not to add an additional grading load on an already difficult assignment.

Instead informal methods would be used to identify and correct those not doing their share. At the start of the course it would be made clear that everyone must contribute. At any time it was expected that each team member should be able to discuss all components of the project to some level of detail. While it is recognized that individuals would know more about the components they did the detail work on, all must know the project. Directing specific questions at individuals rather than the team would be used for enforcement of the individual accountability. The process would be started during informal progress meetings with the coordinators. It would be made clear that a similar approach would be taken during formal presentations. The idea was that students would not want to look bad in front of their peers or the industry sponsors.

Project selection was addressed next. The first project was reasonable overall however it had some weaknesses in its limited breadth. It did not have a transportation component and required some gymnastics to introduce a structural component. The project also had a very large planning component and many of the design aspects did not directly relate back to previous student coursework. While these are not concerns for practicing engineers with a little experience, the students' lack of such experience made these issues important. The original intent was that the nature of the project would force the students to expand their abilities and emphasize the need to 
research specific topics. However, instead of getting the students to put their abilities to work it seemed that, in some cases, the capstone experience hurt some students' confidence in their capability. That result was directly opposite to the intended effect.

To reduce some of these problems, the coordinators actively sought a site development project for the next year's design project. Site development projects can easily incorporate the five basic areas in the Rowan civil engineering curriculum. The type of project would be very similar to what many of the students have touched upon in their internships and would not introduce a tremendous number of new concepts. At the same time the projects would force the students apply and integrate much of what they have learned into a solution to a real problem. Site development also presents the opportunity to introduce issues such as community planning and impacts that may not be addressed in other courses. The coordinators would also work closely with the industry sponsors to simplify some constraints and provide data. Design issues that had not yet been addressed in other classes were identified and training sessions on these topics were planned. The coordinators also worked with the sponsors to identify any "surprises" the students were likely to cross as the project developed.

A large, open-ended project often appears overwhelming to the student project team. Unfortunately, instead of taking a deep breath, getting organized, and coming up with a plan of attack, the teams will often shut down until they must work in crisis mode to meet project deadlines. This occurs at the start of the course and as the project deadlines approach. This problem has not yet been solved. The coordinators have proposed several ways the procrastination might be addressed. One method is the use of more frequent reviews, however, a concern is that this will lead to the students always working in a crisis mode. They may also concentrate their efforts on the review reports or preparation for meetings rather than focusing efforts on the design tasks. The use of staggered deadlines for deliverables is also a possibility. This method would require that calculations, design drawings and reports have different due dates. This would force the students at some point to stop calculating and designing and make sure they get their work on paper. They would then be forced to stop revising drawings and focus their efforts on the written and oral design reports. These possible solutions to the procrastination problem have not yet been implemented.

\section{The Second Rowan CEE Capstone Project and Results}

An engineering consulting firm with several offices in the New Jersey region sponsored the second capstone project in CEE at Rowan University. The project was to develop a 90-acre site of land as a warehouse/distribution center. During the first semester of work the teams were to

- Research municipal development codes and ordinances to assess constraints on the property.

- Perform schematic design analysis to evaluate storm drainage requirements, stormwater detention facilities, access needs, utility considerations, earthwork and grading.

- Submit drawings illustrating the proposed development features such as buildings, parking, access drives and other pertinent site features.

- Identify location, capacity and purveyor of utilities required to develop the property. 
- Prepare a soil boring plan and evaluate the results of the borings.

- Prepare a cost estimate for the project.

The students were provided with design constraints such as a range of building sizes, parking requirements for cars and trucks, and stormwater retention requirements. As an example of a project simplification, the 90 -acre lot was subdivided into three smaller lots that limited the number of options for building placement. The students also received briefing sessions related to hydrologic issues they had not yet encountered in their coursework.

During the second semester the students will address sponsor comments generated in the first semester and also prepare detailed designs for the structures, pavement, and utilities. The site development project is similar to the first project with more planning during the first semester and design work in the second.

Results from the first semester indicated that students still had the same concerns regarding excessive workload, vague guidelines and frustrations by an open-ended project. However the revised student peer evaluation form seemed to successfully evaluate individual student efforts. Evaluations were conducted twice during the semester so slackers could be warned midsemester. This seemed to help weaker students make good faith efforts leading to better overall ratings at the end of the semester. It also eliminated fairness complaints from students about the course grading. The site development project seems successful even though a large number of students felt that their fundamental courses had not prepared them for the challenge of the project. Many students felt that their summer internship positions at local companies had better prepared them for the project. Students also have high expectations from the course coordinators. Since they typically see the same instructors in other traditional courses, they expect the same level of familiarity and assistance on the design project, which may be difficult for faculty outside their area of expertise. It was also difficult for course coordinators to grade technical parts of the written report if they are not familiar with the specific design topic.

\section{Future Plans}

A site development plan seems to be an ideal civil engineering design project. Additional efforts will be made to include social and environmental concerns related to site development. It might also be beneficial to have all faculty members receive some credit for participating in the senior design project especially for the evaluation of the technical written report. An additional adjunct faculty from industry may also be beneficial for the students.

\section{Conclusions}

The Civil and Environmental Engineering program in the College of Engineering at Rowan University has found that site development with an additional structural component makes an excellent capstone design project. The projects often touch on the major traditional areas of civil engineering including geotechnical, water resources, transportation, environmental and structural engineering. The projects allow the students to test and expand their engineering skills without being thrown into design areas with which they are completely unfamiliar. These types of 
projects do not place an increased burden on course instructors to provide significant amounts of additional instruction to keep the project progressing.

The CEE program has also found that an effective peer evaluation system is critical to students' perceptions of grading fairness. Individual assignments are not necessary to determine contributions to a team. However, individual accountability must be emphasized and enforced to assure selected students do not shirk team responsibility. Individual accountability can be achieved through a well-designed peer evaluation system supplemented by other accountability measures such as directed questions.

The capstone design project in CEE at Rowan University is expected to continue to develop and improve as faculty gain additional experience in its administration. Continued ties to industrial sponsors will be important to continue to have a successful capstone. An increased role for all faculty members in the evaluation of the technical content is anticipated as one area for future modification.

Bibliography

1. Accreditation Board for Engineering and Technology, Inc. EAC criteria for 1999 - criteria for accrediting engineering programs. 111 Market Place, Suite 1050, Baltimore, MD, 1999.

2. Black, K. M. An industry view of engineering education. Journal of Engineering Education, v 83, n 1, 1994, pp. 26-28.

3. Katz, S. M. The entry-level engineer: problems in transition from student to professional. Journal of Engineering Education, vol. 82, no. 3, July 1993, pp. 171-174.

4. Knox, Robert C., David A. Sabatini, Ronald L. Sack, Robert D. Haskins, Larry W. Roach and Scott W. Fairbairn. A practitioner-educator partnership for teaching engineering design. Journal of Engineering Education, vol. 84, no. 1, January 1995, pp. 5 - 11.

5. National Research Council. Engineering Education and Practice in the United States: Foundations of Our Techno-Economic Future. Washington, DC, National Academy Press, 1985.

6. National Research Council. Improving Engineering Design. Washington, DC, National Academy Press, 1991.

7. Lang, James D., Susan Cruse, Francis D. McVey and John McMasters. Industry expectations of new engineers: a survey to assist curriculum designers. Journal of Engineering Education, v 88, n 1, 1999, pp. 43 - 51.

8. Todd, R. H., S. P. Magleby, C. D. Sorensen, B. R. Swan and D. K. Anthony. A survey of capstone engineering courses in North America. Journal of Engineering Education, v 84, n 2, 1995, pp. 165 - 174.

9. Dutson, Alan J., Robert H. Todd, Spencer P. Magleby, and Carl D. Sorensen. A review of literature on teaching engineering design through project-oriented capstone courses. Journal of Engineering Education, v 86, n 1, 1997, pp. $17-28$.

10. Knox, Robert C., David A. Sabatini, David E. Hughes, Robert Lambert, and Russ Ketner. Teaching engineering design with practitioner supervision: a case study. Journal of Professional Issues in Civil Engineering Education and Practice, v. 124, n. 4, October 1998, pp. 105 - 109.

11. Morris, C. D. and R. A. LaBoube. Teaching civil engineering design: observations and experiences. Journal of Professional Issues in Engineering Education and Practice, v. 121, n. 1, January 1995, pp. 47 - 53.

12. Napper, Stan D. and Paul N. Hale. Using design projects for program assessment. Journal of Engineering Education, v. 88, n. 2, April 1999, pp. 169 - 172.

13. Kaufman, Deborah B., Richard M. Felder, and Hugh Fuller. Accounting for individual effort in cooperative learning teams. Journal of Engineering Education, v. 89, n. 2, April 2000, pp. 133 - 140.

14. Cleary, Douglas, Ralph Dusseau, Kauser Jahan, Jess Everett, and Beena Sukumaran. Addressing the professional practice criteria of ABET 2000. ASEE Mid-Atlantic Regional Fall Meeting, Harrisburg, PA, November 6, 1999. 


\section{DOUGLAS CLEARY}

Dr. Cleary is an Associate Professor of Civil and Environmental Engineering at Rowan University. He is a registered professional engineer in Indiana and New Jersey and previously worked for Black \& Veatch as a civil and structural engineer. Dr. Cleary is a member of two ACI committees and is faculty advisor to the ASCE student club at Rowan. He received his BSCE, MSCE, and Ph.D. degrees from Purdue University.

\section{KAUSER JAHAN}

Dr. Jahan is an Associate Professor of Civil and Environmental Engineering at Rowan University. She completed her Ph.D. studies in the Department of Civil and Environmental Engineering at the University of Minnesota, Minneapolis in 1993. Dr. Jahan has worked for Harza engineering as a water resources engineer and as an environmental engineer for the Nevada Division of Environmental Protection (NDEP). 